Char act er i zat i on of Samar i um Doped Cer i a Powders havi ng $\mathrm{H}$ gh Speci fi c Surface Area Synt hesi zed by Carbon- assi st ed Spr ay Pyrol ysi s

\begin{tabular}{|l|l|}
\hline 著者 & $\begin{array}{l}\text { MOUJ I K Keni chi, I CH BOSH Hi roki, KODERA } \\
\text { Takayuki, OG HARA Takashi }\end{array}$ \\
\hline $\begin{array}{l}\text { j our nal or } \\
\text { publ i cat i on t i t l e }\end{array}$ & Key Engi neer i ng Nat er i al s \\
\hline vol une & 485 \\
\hline page range & $137-140$ \\
\hline year & $2011-07$ \\
\hline URL & ht t p: //hdl . handl e. net /10098/6826 \\
\hline
\end{tabular}




\title{
Characterization of Samarium Doped Ceria Powders having High Specific Surface Area Synthesized by Carbon-assisted Spray Pyrolysis
}

\author{
Kenichi Myoujin ${ }^{1}$, a , Hiroki Ichiboshi ${ }^{1}$, Takayuki Kodera ${ }^{1}$ and Takashi Ogihara ${ }^{1, b}$ \\ ${ }^{1}$ Faculty of Engineering, University of Fukui, 3-9-1 Bunkyo, Fukui-shi, Fukui, 910-8507, Japan \\ amyoo@u-fukui.ac.jp, bogihara@matse.u-fukui.ac.jp
}

Keywords: Solid oxide fuel cell, Carbon-assisted Spray pyrolysis, Ceria, Samarium, Fine-powders

\begin{abstract}
Spherical samarium doped ceria $\left(\mathrm{Ce}_{0.8} \mathrm{Sm}_{0.2} \mathrm{O}_{1.9}, \mathrm{SDC}\right)$ powders having high specific surface area (SSA) were successfully synthesized by carbon-assisted spray pyrolysis (CASP). Saccharides, such as monosaccharides and disaccharides, or organic acids were used as carbon sources. The physical and chemical properties of these powders were investigated using X-ray diffraction (XRD), scanning electron microscopy (SEM), Thermo gravimetry-Differential Thermal Analysis (TG-DTA), and BET. Decarbonized powders obtained by this method exhibit spherical morphologies and nano- and submicron-sizes. The SSA of SDC obtained from CASP was more than seven times higher than that obtained from conventional spray pyrolysis (CSP). The SSA of the decarbonized SDC powders obtained by calcination at $900{ }^{\circ} \mathrm{C}$ was estimated to be approximately 70 $\mathrm{m}^{2} / \mathrm{g}$ by using the BET method. The relative density of SDC obtained from CASP was higher than that obtained from CSP. The relative density of the SDC pellet was highest $(96 \%)$ when it was sintered at $1400{ }^{\circ} \mathrm{C}$.
\end{abstract}

\section{Introduction}

Solid oxide fuel cells (SOFCs) have attracted much attention as energy conversion devices because of their higher conversion efficiency and low environmental impact. In typical high-temperature SOFCs, yttria-stabilized zirconia (YSZ) is used as the electrolyte [1-3]. Samarium doped ceria $\left(\mathrm{Ce}_{0.8} \mathrm{Sm}_{0.2} \mathrm{O}_{1.9}\right.$, SDC) ceramics are known to have superior oxygen ion conducting properties compared to YSZ electrolytes. However, SDC powders synthesized via conventional solid-state reactions need to be densified by prolonged heating at temperatures as high as $1600-1800{ }^{\circ} \mathrm{C}$ in order to achieve the required chemical homogeneity and desirable density [4]. Such high sintering temperatures restrict microstructural control of the resulting ceramics. If dense SDC electrolytes can be prepared at lower temperatures, it will be easy to co-sinter them with the electrode material, which will simplify the procedure and reduce the costs of fabricating the SOFCs. Nano-sized SDC powders are expected to exhibit rapid densification kinetics, lower sintering temperatures, finer microstructures, and superior properties of the sintered materials compared with bulk SDC powders. Thus, in recent years, several methods have been attempted for synthesizing different types of SDC powders, such as the conventional solid-state reaction, and the sol-gel [5] and hydrothermal syntheses [6]. Spray pyrolysis is known to be useful in the rapid production of multi-component powders in a continuous process [7-8]. The advantages of spray pyrolysis are: (a) spherical morphologies, (b) narrow particle-size distribution, (c) easy preparation of powders with complex compositions, and (d) relatively homogeneous compositions.

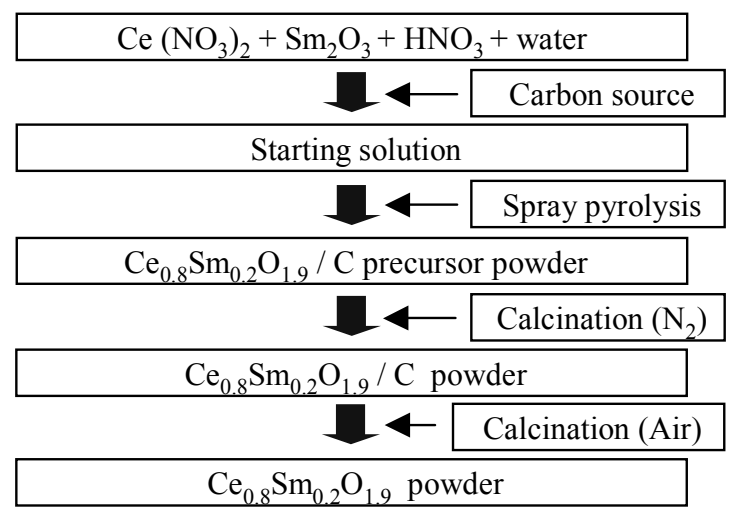

Fig.1 Flow diagram for the preparation of $\mathrm{Ce}_{0.8} \mathrm{Sm}_{0.2} \mathrm{O}_{1.9}$ powder by carbon-assisted spray pyrolysis However, synthesis of nano-sized SDC powders 

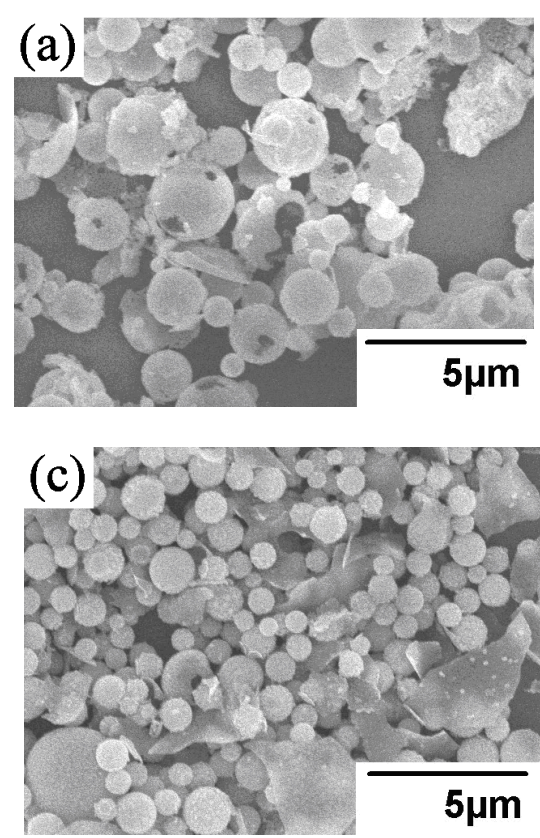
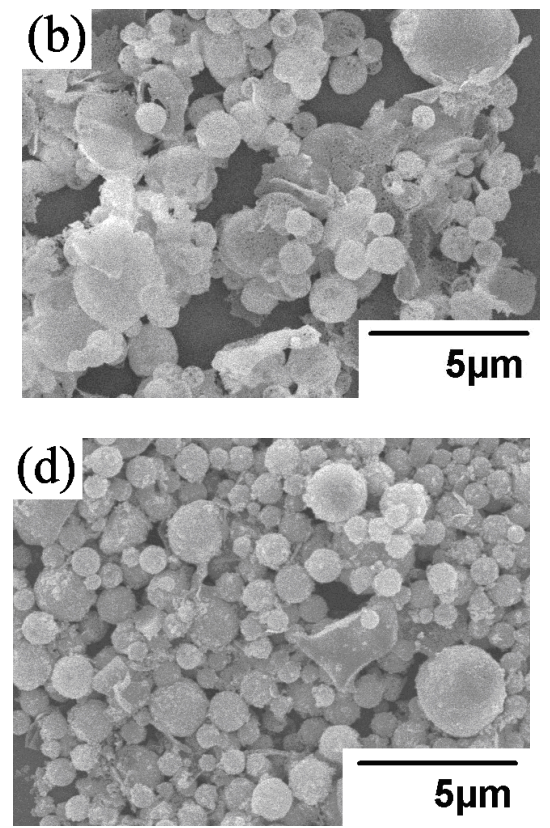

Fig. 2 SEM images of SDC/C powders derived from

(a)citric acid (b)malic acid (c)fructose (d)sucrose

using spray pyrolysis is relatively complicated than that using conventional spray pyrolysis (CSP). On the other hand, a previous research on spray pyrolysis proved that carbon composite powders calcined in an oxygen-free atmosphere successfully obtained high-surface area powders [9].

In this study, SDC powders having high specific surface area (SSA) were synthesized by carbon-assisted spray pyrolysis (CASP) using several types of organic compounds as carbon sources. In addition, the influence of the high SSA of nano-sized particles on the sinterability of SDC was investigated.

\section{Experimental}

In the synthesis of SDC powders, stoichiometric Table 1 Specific surface area of SDC/C powders derived from various carbon

\begin{tabular}{|c|c|}
\hline \multicolumn{2}{|c|}{ sources } \\
Carbon source & $\mathbf{S S A}\left(\mathbf{m}^{2} / \mathbf{g}\right)$ \\
\hline Citric acid & 8.1 \\
\hline Malic acid & 10.9 \\
\hline Fructose & 149.3 \\
\hline Sucrose & 148.3 \\
\hline
\end{tabular}
amounts of metal nitrates were used as starting materials and were dissolved in distilled water containing nitric acid. Carbon sources such as sucrose, fructose, citric acid, and malic acid were added to the aqueous solution until its concentration reached $100 \mathrm{wt} \%$. The starting solution was misted in an ultrasonic nebulizer at a frequency of 1.6 $\mathrm{MHz}$ and carried into an electrical furnace by air at a flow rate of $7.0 \mathrm{dm}^{3} / \mathrm{min}$. The pyrolysis temperature was 500 or $600{ }^{\circ} \mathrm{C}$. As-prepared precursor powders were corrected in a cyclone and calcined at $900{ }^{\circ} \mathrm{C}$ for $10 \mathrm{~h}$ in a furnace under a nitrogen atmosphere. The overall preparation scheme is illustrated in Fig. 1. The crystal phases of the as-prepared and calcined powders were identified by powder X-ray diffraction (XRD, Shimadzu, XRD-6100) using $\mathrm{CuK} \alpha$ radiation. Particle sizes and morphologies were determined by scanning electron microscopy (SEM, JEOL, JSM-6390YH). The average particle size was

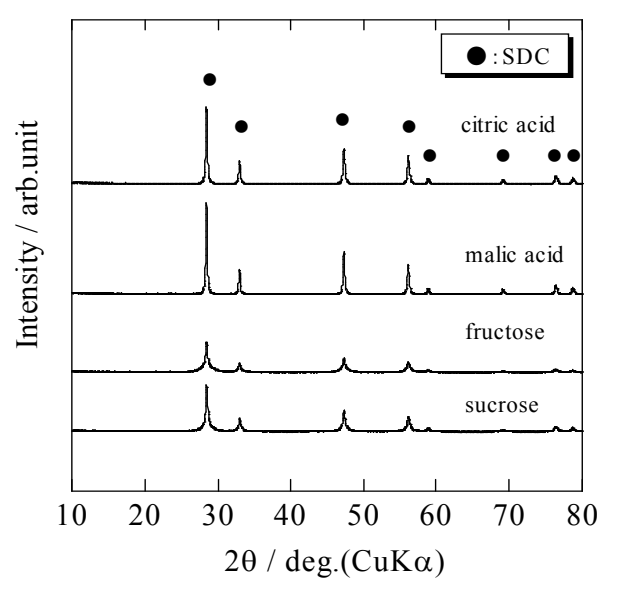

Fig. 3 XRD patterns of SDC/C powders derived from various carbon sources 
determined using a fiber-optics particle analyzer (Otsuka Electronics, FPAR-1000). The SSA of the as-prepared powders was measured by the BET method using $\mathrm{N}_{2}$ adsorption (SSA, BEL, BELSORP-miniII).

\section{Results and Discussion}

Figure 2 shows the SEM images of SDC/C powders obtained by calcination at $900{ }^{\circ} \mathrm{C}$ under a nitrogen atmosphere. The SEM images indicated that all SDC/C powders possessed irregular particle morphologies. The average particle size of SDC/C powders derived from saccharides (Figs. (c), (d)) was smaller than that derived from organic acids (Figs. (a), (b)).

Table 1 shows the SSA of SDC/C powders derived from various carbon sources. The average SSA of SDC/C powders derived from organic acids was smaller than that derived from saccharides. The SSA of the SDC/C powders derived from saccharides was estimated to be approximately $150 \mathrm{~m}^{2} / \mathrm{g}$ by using the BET method.

Figure 3 shows the XRD patterns of SDC/C powders derived from various carbon sources. The as-prepared precursor powders were amorphous but were well-crystallized by calcination under a nitrogen atmosphere. XRD revealed that the diffraction patterns of all samples agreed well with cubic fluorite structures $\left(\mathrm{CeO}_{2}\right.$ peaks), and no other phases were observed. Therefore, no peaks for crystalline carbon appeared in the diffraction pattern throughout the temperature range; this indicates that the carbon generated from organic materials is amorphous and that the presence of carbon does not influence the crystal structure of SDC.

Figure 4 shows the SSA of SDC/C (derived from sucrose) calcined powders obtained by pyrolysis at 500 or $600{ }^{\circ} \mathrm{C}$. The SSA of SDC/C powders gradually increased with increasing calcination temperature. This result is believed to be caused by the carbonization of organic compounds, which occurred at a higher temperature. The SSA of SDC/C powders obtained by pyrolysis at $500{ }^{\circ} \mathrm{C}$ was higher than that obtained at $600{ }^{\circ} \mathrm{C}$, except for calcination at $700^{\circ} \mathrm{C}$.

Figure 5 shows the SEM images of SDC/C powders obtained by calcination at $500{ }^{\circ} \mathrm{C}$ under an air atmosphere. It can be seen that the surfaces of the calcined powders do not appear as fine particles. This result is believed to be caused by the combustion of carbon particles. The calcined powders exhibited porous surfaces and appeared to be agglomerates of the primary particles, which were connected to each other.

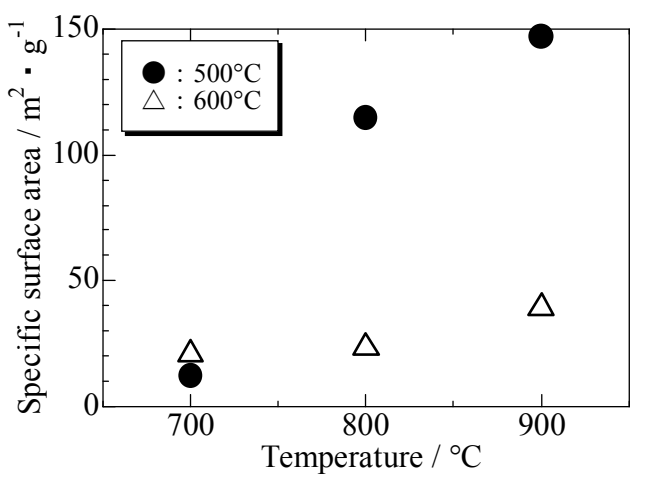

Fig. 4 Specific surface area of SDC/C calcined powders (pyrolysis temperature 500 or $600{ }^{\circ} \mathrm{C}$, sucrose, $\mathrm{N}_{2}$ )
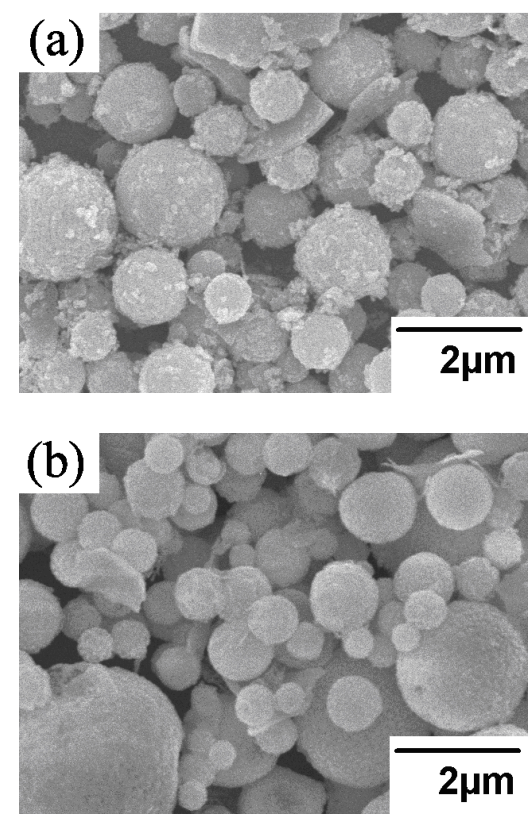

Fig. 5 SEM images of SDC powders derived from sucrose (a)SDC/C (b)after calcination in air

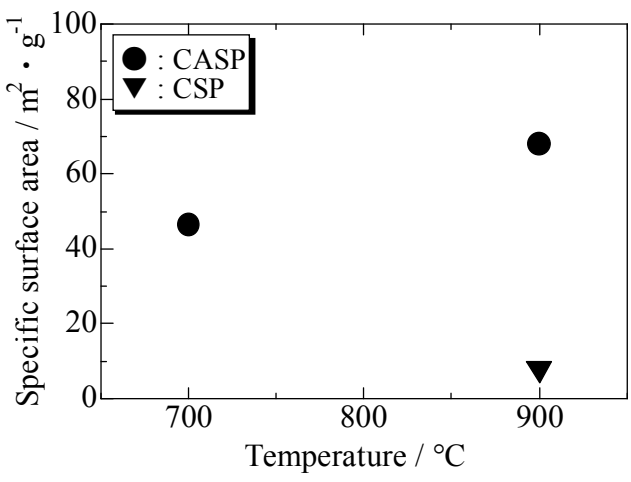

Fig. 6 Specific surface area of SDC powders synthesized by CASP and CSP 
Therefore, the carbon molecules seem to retard the agglomeration between the primary nano-sized crystallites.

Figure 6 shows the SSA of SDC powders. The SSA of SDC obtained from CASP was more than five times higher than that obtained from CSP. The SSA of the decarbonized SDC powders obtained by calcination at $900{ }^{\circ} \mathrm{C}$ was estimated to be approximately $70 \mathrm{~m}^{2} / \mathrm{g}$ by using the BET method.

Figure 7 shows the relative density of SDC pellets sintered at various temperatures for $10 \mathrm{~h}(0.1$ $\left.\mathrm{mol} / \mathrm{dm}^{3}\right)$. The relative density of SDC obtained from CASP was higher than that obtained from CSP. The relative density of SDC pellets was highest (96\%) when the powder was sintered at $1400{ }^{\circ} \mathrm{C}$.

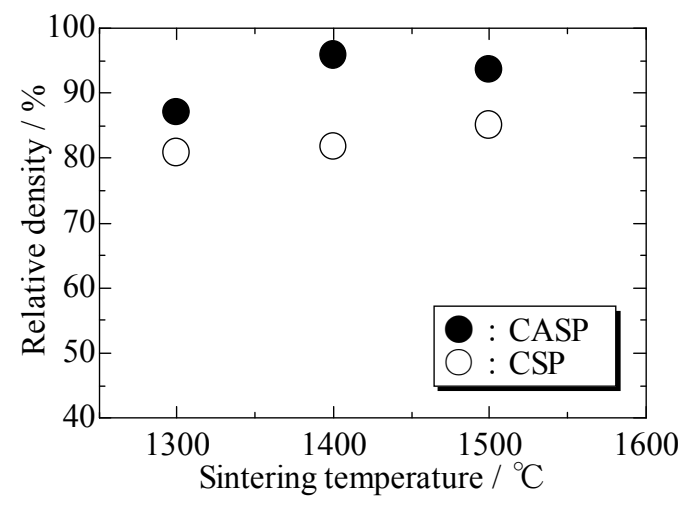

Fig. 7 Relative density of SDC pellets sintered at various temperatures for $10 \mathrm{~h}\left(0.1 \mathrm{~mol} / \mathrm{dm}^{3}\right)$

\section{Conclusion}

Spherical SDC powders having high SSA were successfully prepared by CASP. Saccharides, such as monosaccharides and disaccharides, or organic acids were used as carbon sources. The average SSA of SDC/C powders derived from organic acids was lower than that derived from saccharides. The decarbonized powders obtained by this method exhibit spherical morphologies and nano- and submicron-sizes. The SSA of SDC powders obtained from CASP was more than seven times higher than that obtained from CSP. The SSA of the decarbonized SDC powders obtained by calcination at $900{ }^{\circ} \mathrm{C}$ was estimated to be approximately $70 \mathrm{~m}^{2} / \mathrm{g}$ by using the BET method. The relative density of SDC obtained from CASP was higher than that obtained from CSP. The relative density of the SDC pellet was highest $(96 \%)$ when it was sintered at $1400^{\circ} \mathrm{C}$.

\section{Acknowledgment}

This work was supported by Strategic infrastructure technology sophistication support business in Ministry of Economy, Trade and Industry.

\section{References}

[1] S. C. Singhal: Solid State Ionics, Vol. 135 (2000), p. 305

[2] M. C. Williams, S. C. Singhal and M. Dokiya: Electrochem. Soc., 3 (1999)

[3] A. J. Appleby: Energy, Vol. 21 (1996), p. 521

[4] Z.L. Zhan, T.L. Wen, H.Y. Tu, Z.Y. Lu: J. Electrochem. Soc., Vol. 148 (2001), p. 427

[5] K.Q. Huang, M. Feng, J.B. Goodenough: J. Amer. Ceram. Soc., Vol. 81 (2)(1998), p. 357

[6] M. Hirano, Y. Fukuda, H. Iwata, Y. Hotta, M. Inagaki: J. Am. Ceram. Soc., Vol. 83 (2000), p. 1287

[7] G. L. Messing, S. C. Zhang and G. V. Javanthi: J. Am. Ceram. Soc., Vol. 76 (1993), p. 2707

[8] H. Ishizawa, O. Sakurai, N. Mizutani and M. Kato: Am. Ceram. Soc. Bull., Vol. 65 (1986), p. 1399

[9] K. Egawa, I. Mukoyama, T. Kodera, K. Myoujin and T. Ogihara: Key Engineering Materials, Vol. 388 (2009), p. 81 
Electroceramics in Japan XIV

doi:10.4028/www.scientific.net/KEM.485

Characterization of Samarium Doped Ceria Powders Having High Specific Surface Area Synthesized by Carbon-Assisted Spray Pyrolysis

doi:10.4028/www.scientific.net/KEM.485.137 